\title{
Impact of climate change on the water resources of the Auckland region of New Zealand - a case study
}

\author{
B. Mahmood \\ School of Built Environment, Unitec New Zealand, \\ Auckland, New Zealand
}

\begin{abstract}
In this century, global warming is one of the biggest environmental problems which is always puzzling human being. The focus of this study was to determine the potential impact of climate change on water resources in the Auckland Region. The results showed that the total amount of $\mathrm{CO}_{2}$ in the air is increased by $16.6 \%$ since 1970 . It is estimated to increase to $400 \mathrm{ppm}$ by 2020 in the Auckland Region. The amount of $\mathrm{CH}_{4}$ and $\mathrm{N}_{2} \mathrm{O}$ were 1739 and 322 ppb (parts per billion), respectively, in 2006 . The mean temperature has increased by $1.5^{\circ} \mathrm{C}$ over the last century. It is estimated that the future temperature of the Auckland Region will increase by $0.15^{\circ} \mathrm{C}$ by 2020 . The results also showed that the average annual rainfall in the Region varied between 1241 and $1276 \mathrm{~mm}$ since 1925. Overall trend in sea level rise is $1.4 \mathrm{~mm}$ per year and it is estimated that it would increase to $1928 \mathrm{~mm}$ by 2020 . From water resources perspective, the study showed no cause for alarm. Possible impacts that may especially affect water planning and project evaluation include changes in precipitation and runoff patterns, sea level rise, and land use and population shifts that may follow from these effects.
\end{abstract}

Keywords: global warming, climate change, water resources, Auckland.

\section{Introduction}

Global warming is caused by greenhouse gases which warm the atmosphere by absorbing some of the thermal radiation emitted from the Earth's surface.

Incoming solar radiation is transmitted through the atmosphere to the Earth's surface. The energy is retransmitted by the Earth's surface as thermal radiation. 
Some of the thermal radiation is absorbed by the greenhouse gases instead of being retransmitted out to space, and so there is a warming of the atmosphere. The important greenhouse gases which are directly influenced by human activities are carbon dioxide $\left(\mathrm{CO}_{2}\right)$, methane $\left(\mathrm{CH}_{4}\right)$, nitrous oxide $\left(\mathrm{N}_{2} \mathrm{O}\right)$, chlorofluorocarbons (CFCs) and ozone. Increased amounts of greenhouse gases in the atmosphere will absorb more thermal radiation, and the earth's surface and the lower atmosphere will warm [7]. The warmed Earth emits radiation upwards, just as a hot stove or bar heater radiates energy. In the absence of any atmosphere, the upward radiation from the Earth would balance the incoming energy absorbed from the Sun, with a mean surface temperature of around $18^{\circ} \mathrm{C}$. The presence of "greenhouse" gases in the atmosphere, however, changes the radiation balance. Heat radiation (infra-red) emitted by the Earth is concentrated at long wavelengths and is strongly absorbed by greenhouse gases in the atmosphere, such as water vapour, carbon dioxide and methane. As a result, the surface temperature of the globe is around $15^{\circ} \mathrm{C}$ on average, $33^{\circ} \mathrm{C}$ warmer than it would be if there was no atmosphere. This is called the natural greenhouse effect [7, 8]. In short, the greenhouse effect is a warming of the earth's surface and lower atmosphere caused by substances such as carbon dioxide and water vapour which let the sun's energy through to the ground but impede the passage of energy from the earth back into space.

\subsection{Have greenhouse gas emissions caused global temperatures to rise?}

Many scientific studies carried out illustrate that Earth's climate has been changing over the last century. Climate change is held responsible for a global increase in surface temperature, a decrease in snow cover and overall an increase in sea level [6]. The 2004 record of global average temperatures as compiled by the Climatic Research Unit of the University of East Anglia and the Hadley Centre of the UK Meteorological Office [3] showed that the global mean surface temperature has increased by between 0.3 and $0.6^{\circ} \mathrm{C}$ since the late 19th century, a change which is unlikely to be entirely natural in origin. The balance of evidence suggests a discernible human influence on global climate. Much of the $10-25 \mathrm{~cm}$ rise in global average sea level over the past 100 years may be related to the rise in global temperature [3]. NIWA reported that the greenhouse gases have continued to increase in the atmosphere [7]. This is due largely to human activities, mostly fossil fuel use, land-use change, and agriculture. About $64 \%$ of the warming effect of greenhouse gas increases over the last 200 years is due to carbon dioxide. The second most important greenhouse gas produced by human activities is methane which accounts for about $19 \%$ of the increased warming. (This is an important aspect of New Zealand's greenhouse gas emissions since sheep and cows produce methane). Greenhouse gas growth in global atmosphere slowed during 1991-1993 but has since picked up again. NIWA research suggests that low methane growth rates were due to a temporary reduction in agricultural burning in the tropics [7]. Warming by greenhouse gases is offset in some regions by a cooling due to small airborne particles generated by burning fuel. These are concentrated around areas of industrial activity in the Northern Hemisphere and in developing countries. The cooling effect of aerosols over the 
New Zealand region is expected to be small. The global warming in New Zealand (NZ) may have an impact on aspects that are related to the changing of water resources and climate change is expected to change rainfall patterns over the country. Therefore, the focus of this study was to determine the potential impact of climate change on water resources in the Auckland Region. This paper covers the definition of natural greenhouse effect, 'has greenhouse gas emission caused global warming?' the available water resources in the Auckland Region, and how these might change in the nearer future. A brief discussion of climate change impacts in New Zealand and globally is also covered in the paper.

\section{Methodology}

\subsection{Auckland region weather and data collection}

Auckland's sunniest days occur during anticyclonic conditions in a light southeasterly flow. Due to minor causes (e.g. sea breeze convergence zones or an anticyclonic subsidence inversion) local variations in wind direction and cloud cover may occur, but fine weather predominates. Over twelve hours of sunshine in Auckland City. Auckland's heaviest rainfalls occur when there is a depression to the north or north-west with a strong north to north-east wind flow over the city, and a front embedded in the flow. The two most important parameters for the determination of climate change are temperature and rainfall. In mountainous areas of the Region, these are both modified substantially by the prevailing winds, but in a relatively flat region changes in wind direction do not induce much change in the weather unless they are associated with pronounced pressure systems or fronts. Another important factor is the proximity of the sea, which affects the smaller scale weather systems in the Auckland Region. In each of the two most common wind directions, south-west and north-east, air passes over an extensive sea path before reaching a narrow strip of land, and thus air temperatures remain comparatively low in summer and mild in winter under windy conditions. Also, converging sea breezes in summer may cause heavy showers which remain very local, but which often alleviate the dry conditions associated with anticyclones. Thus the Auckland Region is partly protected from climatic extremes because of its physical situation.

The $\mathrm{CO}_{2}, \mathrm{CH}_{4}$ and $\mathrm{N}_{2} \mathrm{O}$ concentrations or mixing ratios (measured in ppm by volume, which is micromole of trace gas per mole of dry air) were measured by NIWA at Baring Head, which is near Wellington Harbour. This site was chosen as a clean-air site, and for winds from the southerly sector the sampled air is representative of the south Pacific basin, unaffected by emissions from NZ or any nearby territory. The data colleted from Baring Head is representative of the air from the surrounding southern ocean so applicable to the area around NZ ( 87 metres above sea level). Baring head is a part of a global network of stations for determining trends in GHG - greenhouse gases concentrations. Because of the unavailability of the data for the Auckland Region, the Wellington data was used in this study. None of the above gases have a significant latitudinal gradient in the extra-tropical Southern Hemisphere, so they can be taking as applying to clean air over Auckland. It should be noted that the mixing ratios of these gases 
for the Auckland Region will be essentially identical to globally averaged mixing ratios of these gases since, because they are so long lived, there is very little regional heterogeneity (Pers. Communication with Greg Bodekar, NIWA, November 30, 2006). The $\mathrm{CO}_{2}$ concentrations were measured continuously in situ (along with meteorological parameters), but for the other gases the discrete samples were collected approximately weekly and analysed in the laboratory. $\mathrm{CO}_{2}$ was measured by non-dispersive infrared spectroscopy, $\mathrm{CH}_{4}$ and $\mathrm{N}_{2} \mathrm{O}$ by gas chromatography (using flame-ionisation and electron-capture detection, respectively). The daily historical data for carbon dioxide, methane and nitrous oxide (GHG) was available for the periods 1970-2006, 1989-2006, and 1996-2006 respectively. The annual mean gas mixing ratios were determined using the daily GHG data for the reporting years. The annual mean temperature and rainfall values were estimated using the daily temperature (1900-2005) and rainfall data (1925-2005) collected at 28 sites located in the Region. The details on these sites can be found in [2]. The annual mean seal level data was also obtained from NIWA for the period 1899 to 2000. Future estimation of GHG concentrations, temperature, rainfall and sea level rise were made using the rate at which these have increased over the past years. The Auckland Regional surface and groundwater resources use and allocation data was obtained from Auckland Regional Conference (ARC). The 30 years average temperature and rainfall data were also collected from the Albert Park weather station of Auckland city for comparison purpose.

\section{Results and discussions}

\subsection{Concentrations of $\mathrm{CO}_{2}, \mathrm{CH}_{4}$, and $\mathrm{N}_{2} \mathrm{O}$ Gases}

The results showed that the concentrations of $\mathrm{CO}_{2}$ increased steadily by $16.6 \%$ (i.e. from $325 \mathrm{ppm}$ in 1970 to $379 \mathrm{ppm}$ in 2006) at an average rate of $1.50 \mathrm{ppm}$ per year. If it continues to increase at the same rate then it is estimated that the amount of $\mathrm{CO}_{2}$ will increase to $400 \mathrm{ppm}$ by 2020 in the Region (Figure 1). The concentrations of $\mathrm{CH}_{4}$ and $\mathrm{N}_{2} \mathrm{O}$ were 1739 and $322 \mathrm{ppb}$ in 2006 . From 1989 to now, the $\mathrm{CH}_{4}$ concentrations has risen about by $4.5 \%$ (i.e. 1663.4 to $1739 \mathrm{ppb}$ in 2006) at an average rate of $2.1 \mathrm{ppb}$ per year. The amount of $\mathrm{N}_{2} \mathrm{O}$ has increased on average by $3.4 \%$ at an average rate of $0.3 \mathrm{ppb}$ per year, since 1997 . It is estimated that the level of these two gases (i.e. $\mathrm{CH}_{4}$ and $\mathrm{N}_{2} \mathrm{O}$ ) would increase to 1768 and 326, respectively, by 2020 .

The increasing concentration of $\mathrm{CO}_{2}$ is caused by the burning of fossil fuels (such as oil, gas and coal), increasing number of cars on the road, and the destruction of forests. These activities release large amounts of $\mathrm{CO}_{2}$ into the atmosphere. The main natural source of $\mathrm{CH}_{4}$ is from wetlands. A variety of other sources result directly or indirectly from human activities, for example from ruminant animals (sheep and cows), rice paddies, leakage from natural gas pipelines, and from the decay of rubbish in landfill sites. These emissions continue to increase atmospheric $\mathrm{CH}_{4}$ concentrations. Figure 1 showed that the level of these three gases has gone up at a significant rate over the past years. If extra amounts of greenhouse gases are added to the atmosphere, such as from 
human activities, then they will absorb more of the infra-red radiation. The Earth's surface and the lower atmosphere will warm further until a balance of incoming and outgoing radiation is reached again (the emission of infra-red radiation increases as the temperature of the emitting body rises). This extra warming is called the enhanced greenhouse effect. As the Auckland population is increasing, the energy use from fossil fuels will increase that will continue to lead to dramatic increase in the amount of $\mathrm{CO}_{2}$ in the atmosphere. Similarly, $\mathrm{CH}_{4}$ and $\mathrm{N}_{2} \mathrm{O}$ emission may also increase. It should be noted that about $55 \%$ of NZ's emissions are methane (37.5\%) and nitrous oxide (17.4\%), largely of agricultural origin, which makes NZ GHG profile unusual among developed countries (Ministry for the Environment, 2003).

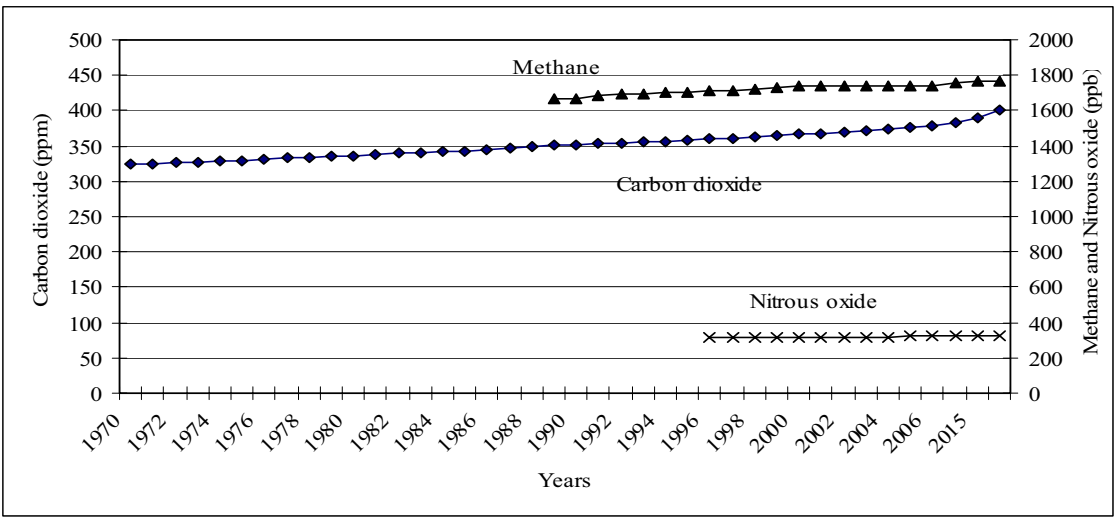

Figure 1: Carbon dioxide, methane and nitrous oxide concentrations for the reporting years. (Source: NIWA).

\subsection{Temperature and rainfall}

The results showed that the mean temperatures of the Region have an unstable increase in the past years. Although there were some temperature decreases but the value has increased from $14.95^{\circ} \mathrm{C}$ in 1900 to $16.3^{\circ} \mathrm{C}$ in 2000 (nearly $1.5^{\circ} \mathrm{C}$ increase over a century). The two temperature decreases were observed in the beginning 20 years and 1970 s to 1980 s of the $20^{\text {th }}$ century. The highest mean temperature was $15.95^{\circ} \mathrm{C}$ in 1970 and the lowest mean temperature was $14.75^{\circ} \mathrm{C}$ in 1920. It is estimated that the future temperature of the Auckland Region will increase by $0.15^{\circ} \mathrm{C}$ by 2020 . It should be noted that the updated 100 years (1906-2005) linear trend of global temperature showed an average increase of $0.74^{\circ} \mathrm{C}\left(0.56-0.92^{\circ} \mathrm{C}\right)[4]$, which is larger than corresponding trends reported by UK Meteorological office [3]. The results showed that the annual mean rainfall varied between 1235 and $1283 \mathrm{~mm}$. In the last century, the average annual rainfall was over $1200 \mathrm{~mm}$. The annual mean rainfall may increase up to $1300 \mathrm{~mm}$ (Figure 2) by 2020. 


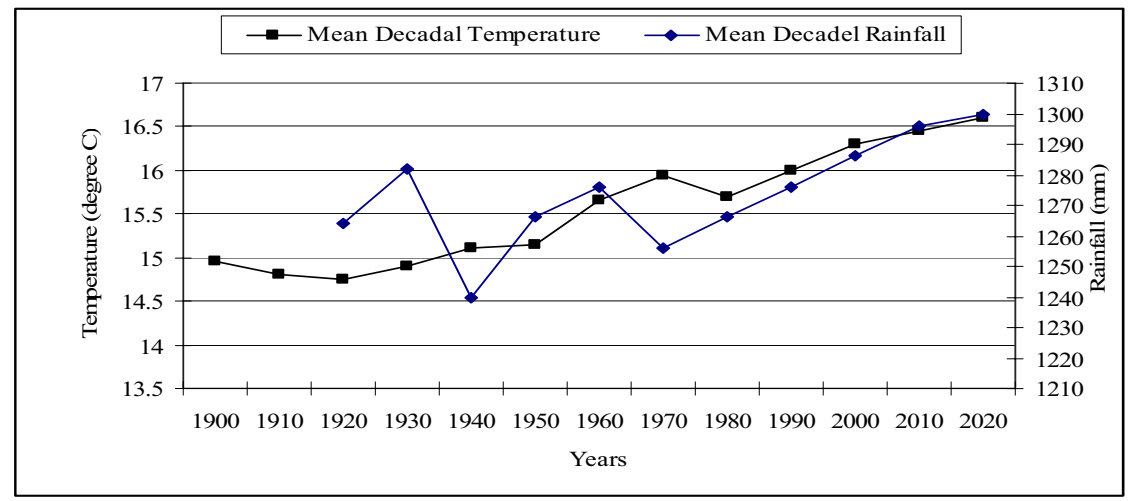

Figure 2: $\quad$ Auckland Region's mean decadal temperature 1900 to 2020) and rainfall (1925-2020) data. (Source: ARC).

\subsection{Sea level rise}

The results showed that the annual mean sea level has risen from $1710 \mathrm{~mm}$ in 1900 to $1900 \mathrm{~mm}$ in 2000 . Overall annual mean sea level has risen by $0.19 \mathrm{~m}$ per century at Auckland port and $0.17 \mathrm{~m}$ per century on average across four main ports of New Zealand. The results showed that the overall trend has been $1.4 \mathrm{~mm}$ rise in sea level per year and it is estimated that it would increase to $1928 \mathrm{~mm}$ by 2020. Higher sea levels and increased storm surges could adversely impact freshwater supplies in some coastal areas of the Region. Saline water profiles in river mouths and deltas would be pushed farther inland, and coastal aquifers would face an increased threat of saltwater intrusion. The intrusion of saltwater into current freshwater supplies could jeopardize the quality of water for some domestic, industrial, and agricultural users. The sea level rise would aggravate water-supply problems in several coastal areas in the Auckland Region, including Manukau Harbour and Hauraki Gulf. It may also adversely affect the Regional groundwater levels. Changes in groundwater levels may damage drainage network and septic tank operations due to changes in groundwater pressure beyond design specifications. This may have negative public health effects, especially if groundwater wells become contaminated. Sea-level changes may also alter pressures within storm water and sewerage systems. And sea-level rise may also pose a threat to wastewater treatment facilities (e.g. oxidation ponds) located on the coast. The global average sea level rose (over the 20th Century) between 0.13 and $0.23 \mathrm{~m}$, with a central value of $0.18 \mathrm{~m}$ per century. The total $20^{\text {th }}$ century rise is estimated to be $17 \mathrm{~cm}$ [4]. Longer overseas records from stable ports in Europe indicate that modern sea levels began rising noticeably in the early to mid-1800s, after a 3,000-year period of relatively slow rise of 0.01 to $0.02 \mathrm{~m}$ per century [10]). The rise in sea level could be due to thermal expansion of the oceans and increased melting of glaciers and land ice. The Auckland sea level increased $19 \mathrm{~cm}$ during the past century (as mentioned earlier) which was largely due to the melting of land-based ice sheets and 
glaciers. The IPCC 1995 assessment report suggests that average sea level might rise another 15 to $95 \mathrm{~cm}$ by the year 2100, with a best guess of about $50 \mathrm{~cm}$ [9]. Whereas, IPCC 2007 projected globally a sea level rise between 18 and $59 \mathrm{~cm}$ (over the $21^{\text {st }}$ century) under different model-based scenarios [4]. These projections were assessed from a hierarchy of models that encompass a simple climate model, several Earth Models of Intermediate Complexity (EMICs), and a large number of Atmosphere-Ocean Global Circulation Models (AOGCMs).

\subsection{Water resources of Auckland region}

The surface water of Auckland Region is composed of rivers, small streams, small lakes and wetlands. There are approximately $10,000 \mathrm{~km}$ of streams in the Region, mostly are the small tributaries (less than two meters wide) found at the heads of catchments. This is because the catchments of the Region tend to be small and short. These streams are more sensitive to abstraction and reduced flow and so need to be closely monitored to make sure that flows are maintained at levels that do not adversely impact on their resident flora and fauna. This is particularly important during the summer when flows are at their lowest and demand for water is at its highest. Whereas, groundwater is directly abstracted for water supply and is well used in the Auckland Region. Most groundwater is abstracted from aquifers in the Franklin and Bombay basalts, Waitemata sandstone, Auckland Isthmus basalts, Pleistocene sands and Kaawa shell beds. The region also has two geothermal fields at Waiwera and Parakai. The ARC has defined those stream catchments that are under pressure from high water use as "high use stream management areas". The details of the high use streams and high use aquifers are not given here because of the length constraints of the paper, but can be found in [1]. Water (both surface and ground water) is allocated and used for a range of purposes in the Auckland Region. These are grouped into five categories; (i) irrigation: including pastures, market gardens, orchards, hot house and nurseries, (ii) community: facilities such as golf course, bowling greens, sports fields and also small community supply, (iii) industry: including quarry dewatering, industrial plants and food processing (pigs and poultry), (iv) municipal: reticulated supplies to the metropolitan area serviced by Watercare Services Ltd. and larger urban centers supplied by Franklin and Rodney District Councils, (v) other: including monitoring, emergency, stock and domestic consents, geothermal and other uses. The results showed that 136 million cubic meters $\left(\mathrm{Mm}^{3}\right)$ of water $\left(106 \mathrm{Mm}^{3}\right.$ of surface and $30 \mathrm{Mm}^{3}$ of groundwater) is allocated each year for all purposes (as mentioned above). The main use of the allocated water in the Region is within domestic households. It is calculated that 77.5 million cubic meters of water is used by 1.23 million people in Auckland households for uses such as drinking, cooking, washing and cleaning, and flush toilets. That equates to 173 litres being used by every person every day. This compares favorably with other cities in New Zealand with average domestic water use closer to $250 \mathrm{l} / \mathrm{p} / \mathrm{d}$. The Auckland population is rising at a rate of 18,000 people per year. It is estimated to increase to 1.7 million by 2020 (at a rate of $2.4 \%$ increase per annum). $92 \%$ and $5 \%$ of the allocated surface water is used for municipal and irrigation purposes, respectively. The rest 
is used for community, industry and other purposes. The results also showed that the amount of groundwater used by different groups varies between 38 and $72 \%$ of the allocated groundwater. The overall average water demand remains just below $54 \%$ of the total allocated groundwater and $93 \%$ of total allocated surface water (overall less than $74 \%$ use of total water allocated). This shows that the available groundwater resources are sufficient to meet the water demands in the Auckland Region. Thus it is expected that there will be no shortage of water over the next few decades. There is a broad agreement that climate change will have major impacts on water resources. Possible impacts that may especially affect water planning and project evaluation include changes in precipitation and runoff patterns, sea level rise, and land use and population shifts that may follow from these effects. Warmer temperatures will accelerate the hydrologic cycle, altering precipitation, the magnitude and timing of runoff, and the intensity and frequency of floods and droughts. Higher temperatures will also increase evapotranspiration rates and alter soil moisture and infiltration rates. It is expected that the future climate change (in terms of increase in temperature and $\mathrm{CO}_{2}$ level) may lead to increased surface water resources of the Region, with high rainfall in the west and less in the east of the region.

\subsection{General discussions}

\subsubsection{Potential impact of climate change in New Zealand and globally}

New Zealand is likely to experience climate changes such as higher temperatures, more in the North Island than the South, (but still likely to be less than the global average); increasing sea levels that are expected to rise (globally) between 18 and $59 \mathrm{~cm}$ by 2100 [4], compared with an average rise of $18 \mathrm{~cm}$ in the 20th century); more frequent extreme weather events such as droughts (especially in the east of New Zealand) and floods; a change in rainfall patterns higher rainfall in the west and less in the east. In the long term, if unchecked, climate change increases the risk of major and irreversible changes to Earth. For example even for relatively moderate warming, the Greenland ice sheet is expected to melt completely over the next several thousand years, which would lead to a sea-level rise of as much as 6-7 $\mathrm{m} \mathrm{[1].} \mathrm{The} \mathrm{cost} \mathrm{of} \mathrm{doing} \mathrm{nothing} \mathrm{about}$ climate change could be severe and the impacts on our environment, economy and society are likely to get steadily worse if greenhouse gas emissions are not reduced significantly over the coming decades. Impacts of climate change will be distributed unevenly around the world with developing nations the most vulnerable. Many leading scientists tell us that there will be both positive and negative consequences of climate change, at least in the short term (their findings are summarised in IPCC reports $[1,4]$. New Zealand is heavily dependent for its economy and therefore on the climate. The severity of climate change impacts will depend on what we and the rest of the world do now to reduce greenhouse gas emissions and how we plan and prepare for the impacts of climate change. While New Zealand only accounts for $0.2 \%$ of greenhouse gas emissions globally, our climate will be affected by the total emissions of all countries not just our own. It is expected to see the flow-on effects of climate change through changing overseas market demands and competition, as well as environmental 
disasters such as droughts and storms becoming more severe. This could lead to increased demands on us for development aid and an increase in environmental refugees. This means it is important for us, and the rest of the world, to encourage and participate in a global agreement like the Kyoto Protocol which is aimed at reducing global greenhouse gas emissions [1].

\subsubsection{New questions}

The debate about climate change has moved from "is it happening?" to the much harder questions of "how many emissions are too much?", "how much is it going to cost?", "what to do about it?", and "who should pay?" On average, New Zealand is already at a concentration of $425 \mathrm{ppm}$ of carbon dioxide equivalent (including the effect of other greenhouse gases) and climbing at more than 2.5 ppm per year. How much more is too much? The size of response of the climate to greenhouse gases is uncertain, so we cannot say what level of emission is safe. However, that uncertainty has been well studied and we can say that, for example, a rise of greenhouse gases to $500 \mathrm{ppm}$ will imply a $70 \%$ chance of exceeding the $2^{\circ} \mathrm{C}$ target. A rise of $450 \mathrm{ppm}$ will mean a $50 \%$ chance [9]. These percentages are themselves uncertain, but it is clear that there are big risks with any increase of emissions. A final note - delaying actions means that by the time we start cutting emissions, there will already be more carbon in the atmosphere. Thus delay requires much harsher cuts.

\section{Summary and conclusions}

It is clear that the Auckland Region water resources planning now and in the foreseeable future will face continued uncertainty about climate change and its impact. However, although planning under an uncertain climate is unavoidable. By identifying the likely climate changes (e.g. rise in temperature, sea level and $\mathrm{CO}_{2}$ level) in the Region, this study provides guidance to planners in terms of possible extremes, best guesses, and more likely direct of change. For example, the greenhouse gases emissions results showed that the level of $\mathrm{CO}_{2}, \mathrm{CH}_{4}$, and $\mathrm{N}_{2} \mathrm{O}$ increased, and will continue to rise as more and more energy being used. The total amount of $\mathrm{CO}_{2}$ in the air is increased by $16.6 \%$ (at a rate of $1.5 \mathrm{ppm} /$ year) since 1970, and this may increase to $400 \mathrm{ppm}$ by 2020 in the Region. The amount of $\mathrm{CH}_{4}$ and $\mathrm{N}_{2} \mathrm{O}$ were 1739 and $322 \mathrm{ppb}$ (parts per billion), respectively, in 2006. It is estimated that the level of these two gases may increase to 1768 and 326, respectively, by 2020. The results showed that a significant shift in the climate of the Region has occurred over the last century. The mean temperature increased by $1.5^{\circ} \mathrm{C}$ over the last century (i.e. from $14.95^{\circ} \mathrm{C}$ in 1900 to $16.3^{\circ} \mathrm{C}$ in 2000 ), and it is estimated that it may increase by $0.15^{\circ} \mathrm{C}$ by 2020 . The average annual rainfall in the Region varied between 1241 and $1276 \mathrm{~mm}$ since 1925, and it may increase to $1300 \mathrm{~mm}$ by 2020. It is known that when climate is warmer, rainfall tends to be heavier because there is more moisture in the atmosphere. The sea level at Auckland port increased by $19 \mathrm{~cm}$ during the past century at a rate of $1.4 \mathrm{~mm}$ rise per year and it is estimated that it may increase to $1928 \mathrm{~mm}$ by 2020 . The results showed that 136 million cubic meters $\left(\mathrm{Mm}^{3}\right)$ of water $\left(106 \mathrm{Mm}^{3}\right.$ of surface and $30 \mathrm{Mm}^{3}$ of groundwater) is 
allocated each year for all purposes. The main use of the allocated water in the Region is within domestic households. The overall average water demand remains just below $54 \%$ of the total allocated groundwater. This shows that the available groundwater resources are sufficient to meet the water demands in the Region. From a water resources perspective, the results suggested no immediate cause for alarm. So, although it is reasonable to conclude that future climate change may lead to increased surface water resources in the Region. The scale of the climate impact may vary from negligible to significant by 2020 (depending on the catchment characteristics and climate change). Thus, it is expected that there will be no substantial decrease in water supply over the next few decades, and even maximum plausible changes to 2020 are unlikely to be critical potential benefits in terms of increased water resources availability seem more likely.

\section{References}

[1] Auckland Regional Authority. (2005), Proposed Auckland Regional Plan: Air, LandandWater. AucklandRegional Authority. Auckland, New Zealand.

[2] Bannister, R. Crowcroft, G. and Johnston, A. (2004), Auckland Water Resources Quantity Statement June 2003 - May 2004. Auckland Regional Council Technical Publication. Auckland, New Zealand.

[3] Climatic Research Unit. (2004), Global Temperature Records. School of Environmental Sciences, University of East Anglia, Norwich, UK.

[4] Intergovernmental Panel on Climate Change (IPCC). (2007), Climate Change 2007: The Physical Science Basis. Summary for Policymakers approved at the $10^{\text {th }}$ Session of Working Group I of the IPCC, Paris, February 2007. IPCC Secretariat, c/o WMO, 7bis, Avenue de la Paix, C.P.N 2300, 1211 Geneva 2, Switzerland.

[5] Ministry for the Environment. (2003). Climate Change National Inventory Report, New Zealand Greenhouse Gas Inventory 1990-2001. Ministry for the Environment, Wellington, New Zealand.

[6] New Zealand Climate Change office. (2006). Climate Change Impacts. Environment House, 23 Kate Sheppard Place, Thorndon PO Box 10362, Wellington, New Zealand.

[7] National Institute of Water and Atmospheric Research (NIWA). (2003). The greenhouse effect a New Zealand perspective on climate change. NIWA Information Series No. 29. ISSN 1174-264x. Wellington, New Zealand.

[8] National Institute of Water and Atmospheric Research (NIWA). (2006). Climate change and global warming. Retrieved July 1, 2006, from http://www.niwascience.co.nz/edu/students/faq/change.

[9] The Royal Society of New Zealand. (2006). Royal Society Alert - Issue 446. Received on October 26, 2006. Also accessible on http://www.rsnz.org/news/sciencealert.php.

[10] Wratt, D. (1998). Intergovernmental Panel on Climate Change (IPCC) Assessments. National Institute of Water and Atmospheric Research. Auckland, New Zealand. 